\title{
The yield of potato plants as affected by stem canker (Rhizoctonia solani), blackleg (Erwinia carotovora subsp. atroseptica) and by neighbouring plants
}

\author{
G. A. HIDE, S. J. WELHAM, P. J. READ AND A. E. AINSLEY \\ IACR-Rothamsted, Harpenden, Herts AL5 2JQ, UK
}

(Revised MS received 5 April 1995)

\begin{abstract}
SUMMAR Y
Potato seed tubers inoculated with Rhizoctonia solani and Erwinia carotovora subsp. atroseptica, to induce stem canker and blackleg respectively, were planted with uninoculated seed tubers in field experiments designed to measure the effects of the diseases and of neighbouring plants on tuber yield. Gaps were also included. The plant variables total and ware $(>150 \mathrm{~g})$ yields and tuber numbers were affected by disease, and also by competition from the two plants on either side in the same row (first neighbours), and increased as competition from neighbouring plants decreased. Plants adjacent to the first neighbours also influenced yields of plants with stem canker but those in adjacent rows did not have a significant effect with either disease. Both diseases altered the tuber size distributions, which were also modified by neighbouring plants. The data were used to predict total and ware yields for crops containing different proportions of healthy, diseased and missing plants.
\end{abstract}

\section{INTRODUCTION}

Yields of potato plants are influenced by diseases that injure the seed tuber and damage the growing crop. Seed tubers commonly carry sclerotia of Rhizoctonia solani Kühn (Hide 1981) and, after planting, the fungus infects developing shoots and causes stem canker. Plants are not killed but crop development is delayed, and tuber initiation and bulking are further delayed by the infection and pruning of stolons (Hide et al. 1985a,b). Similarly, seed tubers commonly carry latent infections of Erwinia carotovora subsp. atroseptica (van Hall) Dye (Pérombelon 1972) and, after planting, bacteria rot the tuber and migrate into stems to cause blackleg. The disease can develop at any time during growth and in the South of England symptoms usually show during July. Plants may be killed but often some stems survive; yield and mean tuber size are decreased (Adams \& Lapwood 1983).

In an experiment in 1987, yield and tuber numbers from Pentland Crown plants were affected by gangrene rots (Phoma foveata Foister) on the seed tubers and also by neighbouring plants (Hide $e t$ al. 1995). Similar experiments were made with seed tubers inoculated with $R$. solani (1987) or $E$. carotovora subsp. atroseptica (1988) to induce stem canker or blackleg respectively.

\section{MATERIALS AND METHODS}

In February 1987, seed tubers cv. Pentland Squire $(40-45 \mathrm{~mm})$ were placed on trays to sprout in fluorescent light at $8^{\circ} \mathrm{C}$. The tubers were planted by hand on 28 April according to a design described by Hide $e t$ al. (1995). An isolate of $R$. solani was grown at $15^{\circ} \mathrm{C}$ for 6 weeks on horticultural vermiculite moistened with $2 \%$ malt extract (Hide et al. 1985a) and, during planting, $50 \mathrm{ml}$ of the inoculum was sprinkled over each seed tuber designated as diseased before covering with soil.

Seed tubers cv. Désirée $(45-50 \mathrm{~mm})$ were similarly sprouted in 1988. Inoculum was prepared by growing isolates of $E$. carotovora subsp. atroseptica on nutrient agar for $24 \mathrm{~h}$. During planting on 28 April 1988, each tuber to be infected was stab inoculated midway between stolon and rose end to a depth of $2 \mathrm{~cm}$ with $0.02 \mathrm{ml}$ of a suspension of $10^{10}$ bacterial cells $/ \mathrm{ml}$ contained in the eye of a steel darning needle (Lapwood et al. 1985). The seed tubers were then planted according to the design specified below.

In both experiments sprays of pre-emergence herbicide, of fungicide to protect against late blight and of haulm desiccant were applied according to local practice from tractor passage rows. Plants were harvested individually on 20-22 October 1987 and 4-6 October 1988 and each tuber was weighed. 
Table 1. Analysis of variance table for total and ware yields, stem canker

\begin{tabular}{lrrr}
\hline & & \multicolumn{2}{c}{$\begin{array}{c}\text { Variance } \\
\text { ratio }\end{array}$} \\
\cline { 3 - 5 } Source & 5 & $9 \cdot 2$ & 15.5 \\
& $\begin{array}{c}\text { Degrees of } \\
\text { freedom }\end{array}$ & Total & Ware \\
\hline Block & 1 & 89.8 & 30.6 \\
Focal plant & & & \\
(healthy/diseased) & 44 & 17.0 & 17.0 \\
Within-row pattern & 5 & 121.0 & 118.4 \\
$\quad$ First neighbours & 5 & 16.4 & 15.7 \\
Second neighbours & 25 & 1.8 & 2.4 \\
$\quad$ First/second neighbours & 9 & 1.6 & 1.8 \\
$\quad$ Remainder & 5 & 0.7 & 0.6 \\
Adjacent row pattern & 44 & 0.9 & 1.0 \\
Focal/within-row pattern & 5 & 1.4 & 1.1 \\
$\quad$ Focal/first neighbours & 39 & 0.9 & 1.1 \\
$\quad$ Remainder & 5 & 1.3 & 1.7 \\
Focal/adjacent row pattern & 991 & - & - \\
Residual & 1095 & - & - \\
Total & & & \\
\hline \hline
\end{tabular}

The purpose of both experiments was to estimate competition effects between individual neighbouring plants within and across rows using three categories of seed tuber: healthy, inoculated or gaps (no seed tuber planted). For each plant, called the focal plant of a pattern, estimates of yield were made on the effect of the two neighbouring plants in each direction within rows and one neighbouring plant in each direction across rows (see Hide et al. 1995, Fig. 1), giving five plants within a row and three plants across rows to consider.

\section{A simple model for inter-plant competition}

Hide et al. (1995) showed that for individual plants grown from seed affected with gangrene, a simple linear model which allowed for interference from neighbouring plants could significantly improve the prediction of yield from individual plants compared with a model which ignored interference. In this paper we use the same model to examine interference with two other diseases.

Table 2. Effect of neighbouring plants on tuber yields and numbers of stems and tubers, stem canker

\begin{tabular}{|c|c|c|c|c|c|c|}
\hline \multirow[b]{2}{*}{ Focal plant } & \multicolumn{2}{|c|}{ Total yield/plant (g) } & \multicolumn{2}{|c|}{ Stems/plant } & \multicolumn{2}{|c|}{ Total tubers/plant } \\
\hline & Healthy & Diseased & Healthy & Diseased & Healthy & Diseased \\
\hline & \multicolumn{6}{|c|}{ First neighbours } \\
\hline${ }^{*} \mathrm{OFO}^{*}$ & 2782 & 2785 & $3 \cdot 4$ & 3.6 & 14.8 & $15 \cdot 4$ \\
\hline${ }^{*} \mathrm{OFD}{ }^{*}$ & 2423 & 2121 & $3 \cdot 4$ & $3 \cdot 1$ & 14.9 & 11.9 \\
\hline${ }^{*} \mathrm{OFH}^{*}$ & 2375 & 2125 & 3.4 & 3.0 & 15.6 & 12.5 \\
\hline${ }^{*} \mathrm{DFD}^{*}$ & 1935 & 1710 & 3.0 & 2.9 & $14 \cdot 1$ & $11 \cdot 3$ \\
\hline${ }^{*} \mathrm{DFH}^{*}$ & 1900 & 1554 & $3 \cdot 1$ & $2 \cdot 6$ & $14 \cdot 6$ & 11.5 \\
\hline${ }^{*} \mathrm{HFH}^{*}$ & 1836 & 1488 & $3 \cdot 2$ & $3 \cdot 1$ & $13 \cdot 3$ & $10 \cdot 4$ \\
\hline \multirow[t]{2}{*}{ Mean S.E.D. (99| D.F.) } & \multicolumn{2}{|c|}{94.5} & \multicolumn{2}{|c|}{0.25} & \multicolumn{2}{|c|}{0.88} \\
\hline & \multicolumn{6}{|c|}{ Second neighbours } \\
\hline $\mathrm{O}^{*} \mathrm{~F}^{*} \mathrm{O}$ & 2590 & 2209 & $3 \cdot 7$ & 3.1 & $16 \cdot 3$ & 12.4 \\
\hline $\mathrm{O}^{*} \mathrm{~F}^{*} \mathrm{D}$ & 2203 & 2038 & $3 \cdot 3$ & 3.0 & 146 & 13.1 \\
\hline $\mathrm{O}^{*} \mathrm{~F}^{*} \mathrm{H}$ & 2344 & 1987 & $3 \cdot 2$ & $2 \cdot 9$ & 14.8 & 11.3 \\
\hline$D^{*} F^{*} D$ & 2041 & 1879 & $3 \cdot 0$ & $3 \cdot 2$ & 13.8 & $12 \cdot 7$ \\
\hline$D^{*} F^{*} H$ & 1993 & 1833 & $3 \cdot 1$ & $3 \cdot 2$ & $13 \cdot 3$ & $12 \cdot 2$ \\
\hline $\mathrm{H}^{*} \mathrm{~F}^{*} \mathrm{H}$ & 2078 & 1819 & $3 \cdot 4$ & 2.9 & 14.6 & 11.3 \\
\hline \multirow[t]{2}{*}{ Mean S.E.D. (991 D.F.) } & \multicolumn{2}{|c|}{94.9} & \multicolumn{2}{|c|}{0.25} & \multicolumn{2}{|c|}{0.89} \\
\hline & \multicolumn{6}{|c|}{ Adjacent rows } \\
\hline $\mathrm{OFO}$ & 2342 & 1965 & $3 \cdot 6$ & 3.0 & 16.7 & $12 \cdot 0$ \\
\hline OF D & 2139 & 2064 & $3 \cdot 1$ & 3.0 & 14.5 & $12 \cdot 2$ \\
\hline $\mathrm{OFH}$ & 2204 & 1927 & $3 \cdot 0$ & $3 \cdot 1$ & 13.8 & $12 \cdot 5$ \\
\hline DF D & 2214 & 1964 & $3 \cdot 2$ & $3 \cdot 1$ & 14.1 & $12 \cdot 0$ \\
\hline D F H & 2192 & 1900 & $3 \cdot 4$ & $2 \cdot 9$ & $14 \cdot 2$ & 11.5 \\
\hline $\mathrm{HFH}$ & 2159 & 1962 & $3 \cdot 3$ & $3 \cdot 3$ & 14.1 & 12.9 \\
\hline Mean S.E.D. (991 D.F.) & \multicolumn{2}{|c|}{87.3} & \multicolumn{2}{|c|}{0.23} & \multicolumn{2}{|c|}{0.82} \\
\hline Overall means & 2208 & 1964 & $3 \cdot 3$ & $3 \cdot 0$ & 14.6 & $12 \cdot 2$ \\
\hline S.E.D. & \multicolumn{2}{|c|}{$44 \cdot 3$} & \multicolumn{2}{|c|}{0.12} & \multicolumn{2}{|c|}{0.42} \\
\hline
\end{tabular}

$\mathrm{F}=$ focal plant $; \mathrm{O}=$ no plant $; \mathrm{H}=$ healthy seed tuber $; \mathrm{D}=$ diseased seed tuber.

* Indicates means taken over all combinations of $\mathrm{O}, \mathrm{H}, \mathrm{D}$ in this position. 
The model for yield was broken down into components due to block effects, type of focal plant, type of first neighbour within rows (considered as the six combinations $\mathrm{HH}, \mathrm{HD}, \mathrm{HO}, \mathrm{DD}, \mathrm{DO}, \mathrm{OO}$ where $\mathrm{H}=$ healthy plant, $\mathrm{D}=$ diseased plant and $\mathrm{O}=$ missing plant), the type of second neighbours within rows and neighbours across rows. The model is written as

$$
\text { yield }=\text { block }+ \text { focal } *(\text { first } * \text { second }+ \text { across })
$$

In this notation, $A+B$ indicates a model containing main effects of $A$ and $B$, whereas $A^{*} B$ indicates a model containing main effects plus interactions. This model therefore allows for block effects plus most interactions between the focal plant and its neighbours. Replication of all combinations was insufficient to allow higher-order interactions to be fitted.

\section{Experimental design}

The experiments were designed to enable the effects in the model (1) to be separately estimated. In 1987, a design with six blocks each of $45 \times 8$ plants was generated by computer search as in Hide et al. (1995), with a total of 1096 non-missing focal plants. In 1988, an alternative approach was used to obtain more equal replication of the different patterns and hence more equal precision of estimates. A set of de Bruijn sequences (Hall 1986) of length 247 were found in which each of the possible $3^{5}=243$ five-plant patterns occurred once, and these sequences were used to generate possible designs. Six sequences were chosen at random and each was cut at random into six subsequences 40 plants long, with two guard plants added to complete patterns at each end, giving in total 36 sub-sequences of 44 plants. These sub-sequences were combined at random into six blocks of six rows with two systematic guard rows added on the edges of each block, giving a design of six blocks of $44 \times 8$ plants. A design was considered acceptable when each within-row pattern appeared at least once in each block, giving replication between 6 and 13 over the experiment (compared with between 2 and 54 for the 1987 design), and when the replication of across-row patterns was comparable with the 1987 design (minimum $=18$, maximum $=140$ ). The design chosen had 990 non-missing focal plants, although 30 diseased plants failed to develop and were treated as missing plants. At harvest, the design had 960 nonmissing focal plants with between 4 and 16 replicates of within-row patterns and between 38 and 136 replicates of across-row patterns.

\section{Statistical analysis}

For each variate, the model was fitted using linear regression and the effect of the type of focal plant (healthy/diseased) and competition effects in the model (1) were estimated. Since different patterns of neighbours were not equally replicated, means were predicted from the model (1) for equal pattern replication, and are presented in place of the biased raw means.

Predictions of crop yield for given percentages of diseased and missing plants were calculated using only statistically significant model terms (Hide $e t$ al. 1995). Tables of predicted yields expressed as a percentage of the yield of a healthy crop are presented with an average standard error.

Approximate tuber size was derived from individual tuber weights using a cube-root transformation. All tubers from each plant were then classed in intervals of 1.25 on the cube-root scale, and tuber size distributions produced from all appropriate plants for each neighbour pattern. The distribution was scaled to 50 plants for comparison and plotted with a smoothed curve imposed to show the general trend.

\section{RESULTS \\ Stem canker}

At harvest, stem canker was confirmed on all plants produced by inoculated seed. The disease was also found on a few plants from non-inoculated seed but was seldom severe.

Both total and ware ( $>150 \mathrm{~g}$ ) yields of tubers were greatly influenced by the type of focal plant and also by the type of first and second neighbours (Table 1). The interaction of first and second neighbours was statistically significant using an $F$-test on the variance ratio, but was relatively unimportant and was not included in the final model. No other effects were significant and yields were not affected by plants in adjacent rows. Significant model terms accounted for 43.0 and $41.9 \%$ of the variation in total and ware yields respectively. Although the type of focal plant influenced ware yield less than it influenced total yield, neighbours appeared to have a similar effect on both total and ware yield.

\section{First neighbours}

Uniform infection of plants with stem canker decreased total yield by $7 \%(\mathrm{HHH}=1836 \mathrm{~g} v$. $\mathrm{DDD}=1710 \mathrm{~g}$, Table 2) when considering the effects of first neighbours only. For both healthy and diseased plants, yields increased as the competition from first neighbours decreased, and healthy plants with no first neighbours yielded $52 \%$ more than those with healthy neighbours ( $\mathrm{OHO} v . \mathrm{HHH})$. The increase was slightly greater with diseased plants $(63 \%$ for ODO $v$. DDD) so that total yields from healthy and diseased plants were similar when first neighbours were missing.

Ware yields from healthy and diseased plants were similar both when focal plants had similar neighbours (DDD v. HHH) and also when there were no first neighbours (OHO v. ODO, Table 3); the absence of 
Table 3. Effect of neighbouring plants on ware yield, number of ware tubers and percentage ware yield, stem canker

\begin{tabular}{|c|c|c|c|c|c|c|}
\hline \multirow[b]{2}{*}{ Focal plant } & \multicolumn{2}{|c|}{ Ware yield/plant $(\mathrm{g})$} & \multicolumn{2}{|c|}{$\begin{array}{l}\text { Number of ware } \\
\text { tubers/plant }\end{array}$} & \multicolumn{2}{|c|}{$\%$ Ware yield } \\
\hline & Healthy & Diseased & Healthy & Diseased & Healthy & Diseased \\
\hline & \multicolumn{6}{|c|}{ First neighbours } \\
\hline *OFO* & 2276 & 2229 & $7 \cdot 8$ & $7 \cdot 3$ & 82.0 & $79 \cdot 4$ \\
\hline *OFD* & 1876 & 1717 & $7 \cdot 1$ & $5 \cdot 8$ & $77 \cdot 7$ & $80 \cdot 7$ \\
\hline *OFH* & 1744 & 1636 & $6 \cdot 5$ & $5 \cdot 7$ & $73 \cdot 2$ & $77 \cdot 2$ \\
\hline${ }^{*} \mathrm{DFD}^{*}$ & 1400 & 1296 & $5 \cdot 7$ & $4 \cdot 8$ & 72.6 & $74 \cdot 7$ \\
\hline *DFH* & 1299 & 1105 & $5 \cdot 2$ & $4 \cdot 2$ & $68 \cdot 2$ & $69 \cdot 8$ \\
\hline${ }^{*} \mathrm{HFH}{ }^{*}$ & 1330 & 1047 & $5 \cdot 2$ & 3.9 & 70.7 & $69 \cdot 2$ \\
\hline \multirow[t]{2}{*}{ Mean S.E.D. (99I D.F.) } & \multicolumn{2}{|c|}{$93 \cdot 1$} & \multicolumn{2}{|c|}{0.36} & \multicolumn{2}{|c|}{3.09} \\
\hline & \multicolumn{6}{|c|}{ Second neighbours } \\
\hline $\mathrm{O}^{*} \mathrm{~F}^{*} \mathrm{O}$ & 1957 & 1755 & $7 \cdot 0$ & $5 \cdot 6$ & $74 \cdot 2$ & $76 \cdot 6$ \\
\hline$O^{*} F^{*} D$ & 1661 & 1569 & $6 \cdot 3$ & $5 \cdot 7$ & $74 \cdot 3$ & $76 \cdot 7$ \\
\hline $\mathrm{O}^{*} \mathrm{~F}^{*} \mathrm{H}$ & 1798 & 1595 & $6 \cdot 5$ & $5 \cdot 4$ & 75.8 & $79 \cdot 2$ \\
\hline$D^{*} F^{*} D$ & 1545 & 1360 & $6 \cdot 1$ & $4 \cdot 9$ & $75 \cdot 1$ & $70-4$ \\
\hline $\mathrm{D}^{*} \mathrm{~F}^{*} \mathrm{H}$ & 1489 & 1338 & $5 \cdot 7$ & 49 & 73.8 & $72 \cdot 4$ \\
\hline $\mathrm{H}^{*} \mathrm{~F}^{*} \mathrm{H}$ & 1476 & 1414 & $5 \cdot 9$ & $5 \cdot 1$ & $71 \cdot 1$ & $75 \cdot 6$ \\
\hline \multirow[t]{2}{*}{ Mean S.E.D. (99l D.F.) } & \multicolumn{2}{|c|}{93.6} & \multicolumn{2}{|c|}{$0 \cdot 37$} & \multicolumn{2}{|c|}{$3 \cdot 11$} \\
\hline & \multicolumn{6}{|c|}{ Adjacent rows } \\
\hline $\mathrm{OFO}$ & 1669 & 1417 & $6 \cdot 4$ & $4 \cdot 3$ & $69 \cdot 6$ & $68 \cdot 1$ \\
\hline OF D & 1602 & 1658 & $6 \cdot 3$ & $6 \cdot 0$ & 73.9 & $80 \cdot 4$ \\
\hline $\mathrm{OF} \mathrm{H}$ & 1697 & 1457 & $6 \cdot 2$ & $5 \cdot 2$ & $76 \cdot 8$ & 73.8 \\
\hline DF D & 1670 & 1531 & $6 \cdot 2$ & $5 \cdot 4$ & $74 \cdot 2$ & $77 \cdot 7$ \\
\hline $\mathrm{DFH}$ & 1646 & 1488 & $6 \cdot 3$ & 5.4 & $74 \cdot 3$ & $77 \cdot 2$ \\
\hline $\mathrm{HF} \mathrm{H}$ & 1642 & 1479 & $6 \cdot 2$ & $5 \cdot 4$ & $75 \cdot 4$ & $73 \cdot 8$ \\
\hline Mean S.E.D. (991 D.F.) & \multicolumn{2}{|c|}{$86 \cdot 0$} & \multicolumn{2}{|c|}{0.33} & \multicolumn{2}{|c|}{$2 \cdot 86$} \\
\hline Overall means & 1654 & 1505 & $6 \cdot 3$ & $5 \cdot 3$ & $74 \cdot 0$ & $75 \cdot 2$ \\
\hline S.E.D. & \multicolumn{2}{|c|}{43.7} & \multicolumn{2}{|c|}{$0 \cdot 17$} & \multicolumn{2}{|c|}{1.45} \\
\hline
\end{tabular}

For abbreviations see Table 2 .

first neighbours led to an increase in ware yield of c. $70 \%$.

Stem canker slightly decreased numbers of stems per plant (means, healthy 3.3, diseased 3.0) although differences were not statistically significant and stem numbers were not affected by neighbour competition.

The disease decreased total numbers of tubers by $15 \%$, resulting from a decrease in tubers $<200 \mathrm{~g}$ (Fig. 1). As competition from neighbours decreased, tuber numbers increased more with diseased than healthy plants (Table 2), so that when there were no first neighbours healthy and diseased plants produced similar numbers of tubers.

Numbers of ware-sized tubers from healthy and diseased plants increased with decreasing competition, as did the percentage of yield which fell into the ware category.

Tuber size distributions (Fig. 2) showed that with healthy plants, including one diseased plant as a first neighbour (DHH) slightly increased numbers of tubers $<200 \mathrm{~g}$. With a further decrease in competition, numbers of larger tubers increased and

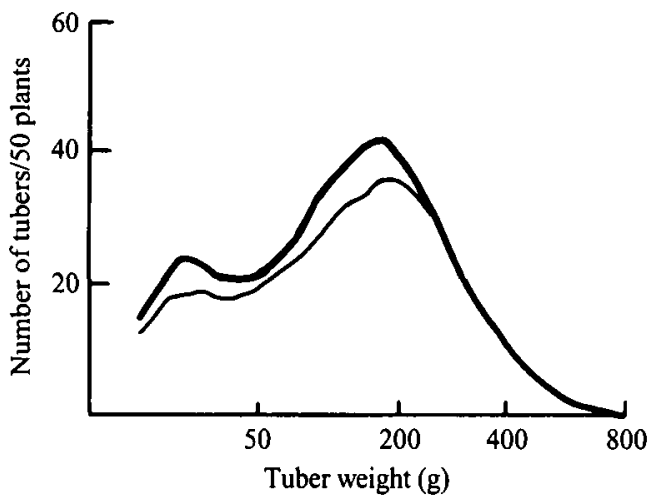

Fig. 1. Size distribution of tubers from healthy plants with healthy first neighbours $(\mathrm{HHH}, \longrightarrow$ ) and from plants with stem canker with diseased first neighbours (DDD, - - ).

numbers of smaller tubers $(25-50 \mathrm{~g})$ declined. With diseased plants, healthy first neighbours decreased numbers of tubers in most sizes, but when the first neighbours included at least one missing plant, 


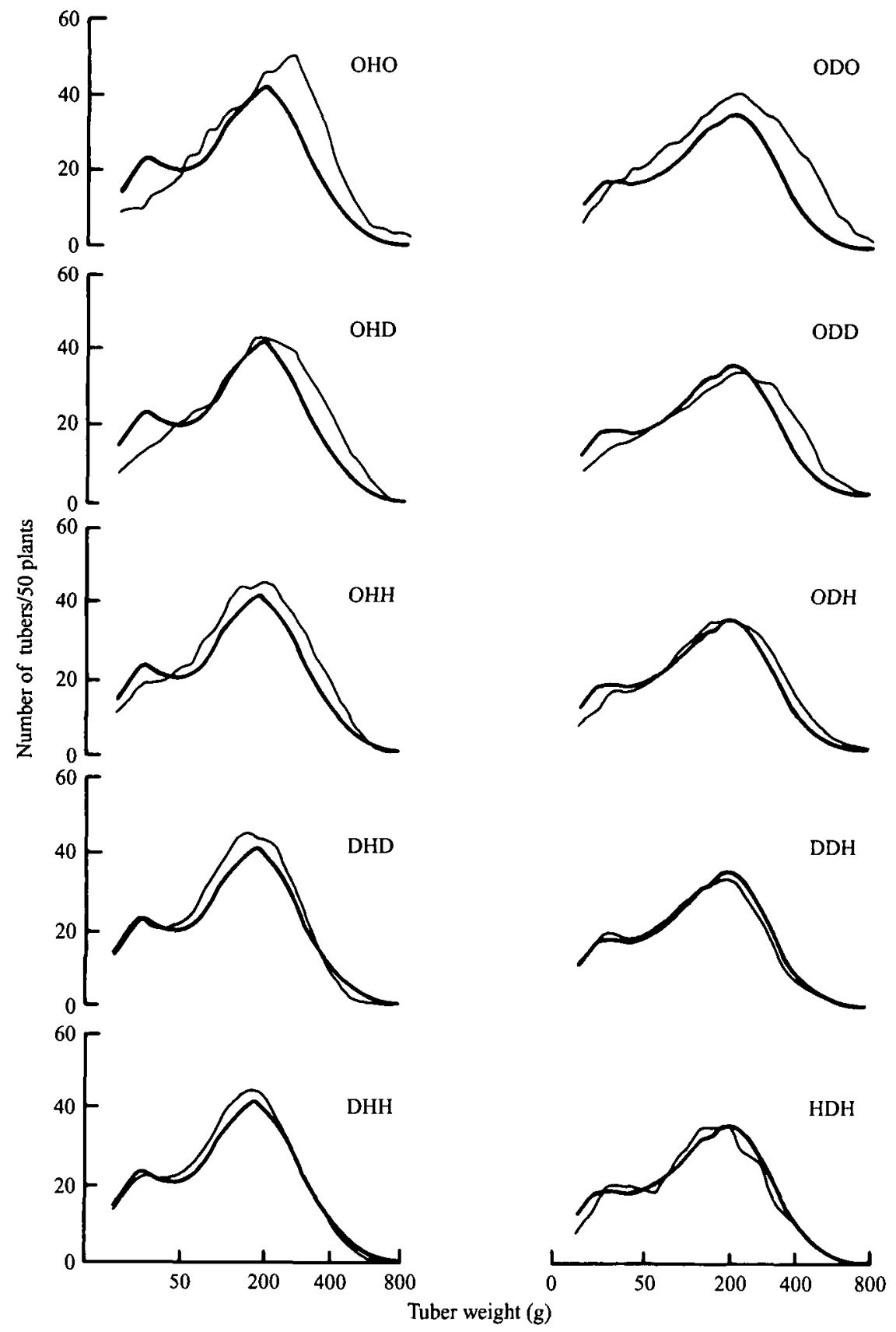

Fig. 2. Size distribution of tubers from healthy plants and from plants with stem canker with different combinations of healthy $(\mathrm{H})$, diseased $(\mathrm{D})$ and missing $(\mathrm{O})$ first neighbours $(-)$. Bold lines $(-)$ show respectively distributions from healthy plants with healthy neighbours $(\mathrm{HHH})$ and diseased plants with diseased neighbours (DDD) as in Fig. 1 .

numbers of tubers $>200 \mathrm{~g}$ were increased and those $<25 \mathrm{~g}$ decreased. When both first neighbours were missing, diseased plants produced more tubers in all sizes $>25 \mathrm{~g}$ and slightly fewer smaller ones.

When healthy and diseased plants had the greatest competition ( $\mathrm{HHH}, \mathrm{HDH})$, patterns of tuber size showed as two populations (Fig. 2). The first population of small tubers declined as neighbour competition decreased and was not detectable when the plants had no first neighbours. 
Table 4. Predicted yields ( $\mathrm{g} / \mathrm{plant}$ position) for different crop mixtures and as percentage of healthy crop yield, stem canker

\begin{tabular}{|c|c|c|c|c|c|c|c|c|c|c|c|}
\hline \multirow{2}{*}{$\begin{array}{l}\text { Missing } \\
\text { plants } \\
(\%)\end{array}$} & \multicolumn{11}{|c|}{ Diseased plants (\%) } \\
\hline & 0 & 10 & 20 & 30 & 40 & 50 & 60 & 70 & 80 & 90 & 100 \\
\hline \multicolumn{12}{|c|}{ Total yield $(\mathrm{g})$} \\
\hline 0 & 1657 & 1646 & 1635 & 1624 & 1614 & 1605 & 1596 & 1588 & 1581 & 1574 & 1568 \\
\hline 10 & 1632 & 1616 & 1602 & 1588 & 1575 & 1562 & 1550 & 1538 & 1527 & 1516 & $*$ \\
\hline 20 & 1575 & 1557 & 1539 & 1522 & 1506 & 1490 & 1475 & 1460 & 1445 & $*$ & * \\
\hline 50 & 1219 & 1195 & 1171 & 1147 & 1124 & 1101 & * & $*$ & $*$ & * & * \\
\hline 60 & 1038 & 1012 & 987 & 962 & 938 & * & * & * & * & * & * \\
\hline \multicolumn{12}{|c|}{ Standard errors: maximum $=49 \cdot 0 ;$ minimum $=10 \cdot 7 ;$ average $=21 \cdot 8$} \\
\hline \multicolumn{12}{|c|}{ Yield as a percentage of healthy crop } \\
\hline 0 & 100 & 99 & 99 & 98 & 97 & 97 & 96 & 96 & 95 & 95 & 95 \\
\hline 10 & 98 & 98 & 97 & 96 & 95 & 94 & 93 & 93 & 92 & 91 & * \\
\hline 20 & 95 & 93 & 93 & 92 & 91 & 90 & 89 & 88 & 87 & $*$ & * \\
\hline 50 & 74 & 72 & 71 & 69 & 68 & 66 & * & * & * & * & $*$ \\
\hline 60 & 63 & 61 & 60 & 58 & 57 & $*$ & * & * & * & * & * \\
\hline \multicolumn{12}{|c|}{ Ware yield (g) } \\
\hline 0 & 1143 & 1142 & 1142 & 1141 & $1141^{\circ}$ & 1141 & 1141 & 1142 & 1142 & 1143 & 1144 \\
\hline 10 & 1160 & 1157 & 1154 & 1152 & 1149 & 1147 & 1145 & 1143 & 1142 & 1141 & $*$ \\
\hline 20 & 1148 & 1143 & 1139 & 1134 & 1130 & 1125 & 1121 & 1118 & 1114 & * & * \\
\hline 50 & 940 & 930 & 920 & 910 & 900 & 891 & $*$ & * & $*$ & * & $*$ \\
\hline 60 & 812 & 800 & 789 & 778 & 767 & * & * & * & * & * & $*$ \\
\hline Standard er & s: $\operatorname{maxi}$ & $\mathrm{dm}=4$ & $\operatorname{minin}$ & $n=10$ & averag & $21 \cdot 6$ & & & & & \\
\hline \multicolumn{12}{|c|}{ Ware yield as a percentage of healthy crop } \\
\hline 0 & 100 & 100 & 100 & 100 & 100 & 100 & 100 & 100 & 100 & 100 & 100 \\
\hline 10 & 101 & 101 & 101 & 101 & 101 & 100 & 100 & 100 & 100 & 100 & $*$ \\
\hline 20 & 100 & 100 & 100 & 99 & 99 & 98 & 98 & 98 & 97 & * & * \\
\hline 50 & 82 & 81 & 80 & 80 & 79 & 78 & * & * & * & * & * \\
\hline 60 & 71 & 70 & 69 & 68 & 67 & * & * & * & * & * & * \\
\hline
\end{tabular}

Table 5. Analysis of variance table for total and ware yields, blackleg

\begin{tabular}{|c|c|c|c|}
\hline \multirow[b]{2}{*}{ Source } & \multirow{2}{*}{$\begin{array}{l}\text { Degrees of } \\
\text { freedom }\end{array}$} & \multicolumn{2}{|c|}{$\begin{array}{l}\text { Variance } \\
\text { ratio }\end{array}$} \\
\hline & & Total & Ware \\
\hline Block & 5 & $4 \cdot 4$ & $6 \cdot 6$ \\
\hline Focal & 1 & $719 \cdot 6$ & $371 \cdot 2$ \\
\hline Within row pattern & 44 & $5 \cdot 1$ & 5.8 \\
\hline First neighbours & 5 & $38 \cdot 2$ & 43.9 \\
\hline Second neighbours & 5 & $1 \cdot 3$ & 1.6 \\
\hline First/second neighbours & 25 & 0.9 & $1 \cdot 0$ \\
\hline Remainder & 9 & 0.4 & 0.6 \\
\hline Adjacent row pattern & 5 & 0.6 & 0.8 \\
\hline Focal/within row pattern & 44 & $1 \cdot 1$ & $1 \cdot 1$ \\
\hline Focal/first neighbours & 5 & 1.5 & 1.5 \\
\hline Remainder & 39 & $1 \cdot 1$ & $1 \cdot 1$ \\
\hline Focal/adjacent row pattern & 5 & $1 \cdot 0$ & 0.8 \\
\hline Residual & 855 & - & - \\
\hline Total & 959 & - & - \\
\hline
\end{tabular}

\section{Second neighbours}

Total and ware yields increased as competition from second neighbours decreased (Tables 2 and 3 ) and, in contrast to the effects of first neighbours, this increase was similar in proportion for healthy and diseased plants. When second neighbours were missing, total and ware yields from diseased plants averaged respectively 15 and $10 \%$ less than from healthy plants. The different combinations of second neighbours did not affect numbers of stems or total numbers of tubers, although numbers of ware sized tubers increased slightly as competition decreased. Ware yield as a percentage of the total yield was slightly greater from diseased than from healthy plants.

\section{Adjacent rows}

There was no trend of increasing yield with decrease in the competition from plants in adjacent rows, and losses in yield and tuber number caused by the disease were similar to those found with second neighbours. 
Potato yields and stem canker and blackleg

Table 6. Effect of neighbouring plants on tuber yields and numbers of stems and tubers, blackleg

\begin{tabular}{|c|c|c|c|c|c|c|}
\hline \multirow[b]{2}{*}{ Focal plant } & \multicolumn{2}{|c|}{ Total yield/plant (g) } & \multicolumn{2}{|c|}{ Stems/plant } & \multicolumn{2}{|c|}{ Total tubers/plant } \\
\hline & Healthy & Diseased & Healthy & Diseased & Healthy & Diseased \\
\hline & \multicolumn{6}{|c|}{ First neighbours } \\
\hline${ }^{*} \mathrm{OFO}^{*}$ & 2497 & 1481 & $3 \cdot 6$ & $2 \cdot 4$ & 16.6 & 10.8 \\
\hline${ }^{*} \mathrm{OFD}{ }^{*}$ & 2267 & 1333 & $3 \cdot 3$ & $2 \cdot 5$ & $15 \cdot 5$ & $9 \cdot 1$ \\
\hline${ }^{*} \mathrm{OFH}^{*}$ & 2101 & 1101 & 3.6 & $2 \cdot 3$ & $15 \cdot 3$ & $8 \cdot 3$ \\
\hline${ }^{*} \mathrm{DFD}^{*}$ & 1951 & 1145 & $3 \cdot 3$ & $2 \cdot 6$ & $15 \cdot 2$ & $10 \cdot 0$ \\
\hline${ }^{*} \mathrm{DFH}^{*}$ & 1800 & 990 & $3 \cdot 4$ & $2 \cdot 6$ & $15 \cdot 4$ & $8 \cdot 2$ \\
\hline${ }^{*} \mathrm{HFH}^{*}$ & 1605 & 817 & $3 \cdot 6$ & $2 \cdot 3$ & $13 \cdot 7$ & 7.2 \\
\hline \multirow[t]{2}{*}{ Mean S.E.D. ( 855 D.F.) } & \multicolumn{2}{|c|}{$93 \cdot 2$} & \multicolumn{2}{|c|}{0.23} & \multicolumn{2}{|c|}{0.76} \\
\hline & \multicolumn{6}{|c|}{ Second neighbours } \\
\hline $\mathrm{O}^{*} \mathrm{~F}^{*} \mathrm{O}$ & 2036 & 1188 & $3 \cdot 4$ & $2 \cdot 4$ & $15 \cdot 0$ & $9 \cdot 2$ \\
\hline $\mathrm{O}^{*} \mathrm{~F} * \mathrm{D}$ & 2116 & 1167 & 3.6 & $2 \cdot 4$ & 15.7 & 8.8 \\
\hline $\mathrm{O}^{*} \mathrm{~F}^{*} \mathrm{H}$ & 1990 & 1128 & $3 \cdot 5$ & $2 \cdot 3$ & 14.9 & 7.9 \\
\hline$D^{*} F^{*} D$ & 2011 & 1231 & $3 \cdot 2$ & $2 \cdot 6$ & 14.2 & $10 \cdot 0$ \\
\hline $\mathrm{D}^{*} \mathrm{~F}^{*} \mathrm{H}$ & 2002 & 1169 & $3 \cdot 7$ & 2.5 & 14.5 & 8.8 \\
\hline $\mathrm{H}^{*} \mathrm{~F}^{*} \mathrm{H}$ & \multirow{2}{*}{\multicolumn{2}{|c|}{$93 \cdot 2$}} & 3.5 & $2 \cdot 3$ & 16.6 & $9 \cdot 0$ \\
\hline \multirow[t]{2}{*}{ Mean S.E.D. (855 D.F.) } & & & \multicolumn{2}{|c|}{0.23} & \multicolumn{2}{|c|}{0.76} \\
\hline & \multicolumn{6}{|c|}{ Adjacent rows } \\
\hline OFO & 2128 & 1184 & 3.8 & $2 \cdot 6$ & $16 \cdot 3$ & $9 \cdot 3$ \\
\hline OFD & 2007 & 1186 & 3.4 & $2 \cdot 3$ & 15.5 & 9.2 \\
\hline $\mathrm{OFH}$ & 2022 & 1115 & $3 \cdot 4$ & $2 \cdot 3$ & 14.9 & $9 \cdot 0$ \\
\hline $\mathrm{DFD}$ & 2082 & 1183 & $3 \cdot 4$ & $2 \cdot 6$ & 14.9 & $9 \cdot 1$ \\
\hline $\mathrm{DFH}$ & 1933 & 1140 & $3 \cdot 4$ & $2 \cdot 4$ & 14.6 & $9 \cdot 1$ \\
\hline $\mathrm{HFH}$ & 2049 & 1059 & $3 \cdot 5$ & $2 \cdot 4$ & 15.5 & $8 \cdot 1$ \\
\hline Mean S.E.D. $(855$ D.F. $)$ & \multicolumn{2}{|c|}{92.7} & \multicolumn{2}{|c|}{0.23} & \multicolumn{2}{|c|}{0.75} \\
\hline Overall means & 2037 & 1144 & $3 \cdot 5$ & $2 \cdot 4$ & $15 \cdot 3$ & $9 \cdot 0$ \\
\hline S.E.D. & \multicolumn{2}{|c|}{$41 \cdot 4$} & \multicolumn{2}{|c|}{$0 \cdot 10$} & \multicolumn{2}{|c|}{0.34} \\
\hline
\end{tabular}

For abbreviations see Table 2.

Prediction of total and ware yields for different crop mixtures

Predictions of yields from different combinations of diseased and missing plants are given in Table 4. As second neighbours significantly affected yields (Table 1), values shown are lower than those given in Tables 2 and 3. For example, the yield of diseased plants with diseased first neighbours and a mean effect of second neighbours was $1710 \mathrm{~g}$, whereas plants in a full population of diseased plants were predicted to yield $1568 \mathrm{~g}$. The results show that diseased and missing plants affected ware yields less than total yields. Whereas crops with all plants diseased yielded $5 \%$ less than healthy crops, ware yield was unaffected. Also, $10 \%$ missing plants slightly increased ware yields which were decreased only when $20 \%$ or more plants were missing.

\section{Blackleg}

Blackleg was common on plants from inoculated seed tubers but most plants produced at least one vigorous stem.
The type of focal plant had the greatest effect on total and ware yields (Table 5). First neighbours were also important but second neighbours, plants in adjacent rows and interactions were not significant.

\section{First neighbours}

In uniform populations, blackleg decreased total yield by $29 \%(\mathrm{HHH}=1605 \mathrm{~g} v . \mathrm{DDD}=1145 \mathrm{~g})$. Yields from both healthy and diseased plants increased as competition from neighbouring plants decreased (Table 6) and the increases were proportionately greater with healthy than diseased plants; healthy plants without first neighbours yielded $56 \%$ more than those with healthy neighbours ( $\mathrm{HHH}=1605 \mathrm{~g}$ $v . \mathrm{OHO}=2497 \mathrm{~g}$ ), whereas in the equivalent comparison with diseased seed the increase was $29 \%$ $(\mathrm{DDD}=1145 \mathrm{~g} v . \mathrm{ODO}=1481 \mathrm{~g})$. Therefore, when first neighbours were missing, healthy plants yielded $40 \%$ more than diseased plants.

Diseased plants had fewer stems than healthy plants but numbers were not affected by neighbouring plants. Diseased plants also had fewer tubers and with both healthy and diseased plants numbers increased as competition from neighbours decreased. 
Table 7. Effect of neighbouring plants on ware yield, number of ware tubers and percentage ware yield, blackleg

\begin{tabular}{|c|c|c|c|c|c|c|}
\hline \multirow[b]{2}{*}{ Focal plant } & \multicolumn{2}{|c|}{ Ware yield/plant (g) } & \multicolumn{2}{|c|}{$\begin{array}{l}\text { Number of ware } \\
\text { tubers/plant }\end{array}$} & \multicolumn{2}{|c|}{$\%$ Ware yield } \\
\hline & Healthy & Diseased & Healthy & Diseased & Healthy & Diseased \\
\hline & \multicolumn{6}{|c|}{ First neighbours } \\
\hline${ }^{*} \mathrm{OFO}^{*}$ & 1956 & 1155 & $6 \cdot 3$ & $3 \cdot 4$ & 74.5 & $72 \cdot 9$ \\
\hline${ }^{*} \mathrm{OFD}^{*}$ & 1764 & 1071 & $6 \cdot 2$ & $3 \cdot 5$ & 76.6 & 77.2 \\
\hline${ }^{*} \mathrm{OFH}^{*}$ & 1552 & 835 & 5.6 & $2 \cdot 8$ & $73 \cdot 3$ & $69 \cdot 7$ \\
\hline${ }^{*} \mathrm{DFD}^{*}$ & 1413 & 784 & $5 \cdot 0$ & $3 \cdot 0$ & $72 \cdot 0$ & $65 \cdot 3$ \\
\hline${ }^{*} \mathrm{DFH}^{*}$ & 1187 & 670 & 4.8 & $2 \cdot 6$ & $63 \cdot 2$ & 61.5 \\
\hline${ }^{*} \mathrm{HFH}^{*}$ & 1057 & 523 & $4 \cdot 3$ & $2 \cdot 2$ & $63 \cdot 7$ & 52.8 \\
\hline \multirow[t]{2}{*}{ Mean S.E.D. (855 D.F.) } & \multicolumn{2}{|c|}{91.9} & \multicolumn{2}{|c|}{0.32} & \multicolumn{2}{|c|}{3.96} \\
\hline & \multicolumn{6}{|c|}{ Second neighbours } \\
\hline $\mathrm{O}^{*} \mathrm{~F}^{*} \mathrm{O}$ & 1516 & 894 & $5 \cdot 4$ & 3.0 & $71 \cdot 3$ & 67.7 \\
\hline $\mathrm{O} * \mathrm{~F} * \mathrm{D}$ & 1544 & 868 & 5.5 & 2.9 & $69 \cdot 8$ & 67.6 \\
\hline $\mathrm{O}^{*} \mathrm{~F}^{*} \mathrm{H}$ & 1437 & 861 & $5 \cdot 2$ & $3 \cdot 0$ & $69 \cdot 2$ & $70 \cdot 0$ \\
\hline$D^{*} F * D$ & 1522 & 896 & 5.4 & $3 \cdot 2$ & $74 \cdot 2$ & $66 \cdot 9$ \\
\hline $\mathrm{D}^{*} \mathrm{~F} * \mathrm{H}$ & 1413 & 876 & $5 \cdot 2$ & 3.1 & $68 \cdot 1$ & $69 \cdot 3$ \\
\hline $\mathrm{H}^{*} \mathrm{~F}^{*} \mathrm{H}$ & 1495 & 642 & 5.6 & $2 \cdot 3$ & $70 \cdot 7$ & 57.8 \\
\hline \multirow[t]{2}{*}{ Mean S.E.D. (855 D.F.) } & \multicolumn{2}{|c|}{91.9} & \multicolumn{2}{|c|}{0.32} & \multicolumn{2}{|c|}{3.96} \\
\hline & \multicolumn{6}{|c|}{ Adjacent rows } \\
\hline OFO & 1569 & 865 & 5.8 & 3.0 & $72 \cdot 2$ & $70 \cdot 3$ \\
\hline$O F D$ & 1423 & 850 & $5 \cdot 1$ & $2 \cdot 8$ & $68 \cdot 3$ & $64 \cdot 3$ \\
\hline OF H & 1481 & 805 & $5 \cdot 3$ & $2 \cdot 7$ & $70 \cdot 1$ & $65 \cdot 4$ \\
\hline D F D & 1551 & 875 & 5.4 & $3 \cdot 0$ & $72 \cdot 0$ & $64 \cdot 9$ \\
\hline D F H & 1401 & 829 & $5 \cdot 2$ & $2 \cdot 8$ & $70 \cdot 2$ & $66 \cdot 1$ \\
\hline H F H & 1504 & 814 & $5 \cdot 3$ & $3 \cdot 0$ & $70 \cdot 4$ & $68 \cdot 4$ \\
\hline Mean S.E.D. $(855$ D.F. $)$ & \multicolumn{2}{|c|}{$91 \cdot 4$} & \multicolumn{2}{|c|}{0.31} & \multicolumn{2}{|c|}{3.94} \\
\hline $\begin{array}{l}\text { Overall means } \\
\text { S.E.D. }\end{array}$ & 1488 & 9840 & $5 \cdot 4$ & $4^{2.9}$ & $70 \cdot 5$ & $76^{66 \cdot 6}$ \\
\hline
\end{tabular}

For abbreviations see Table 2.

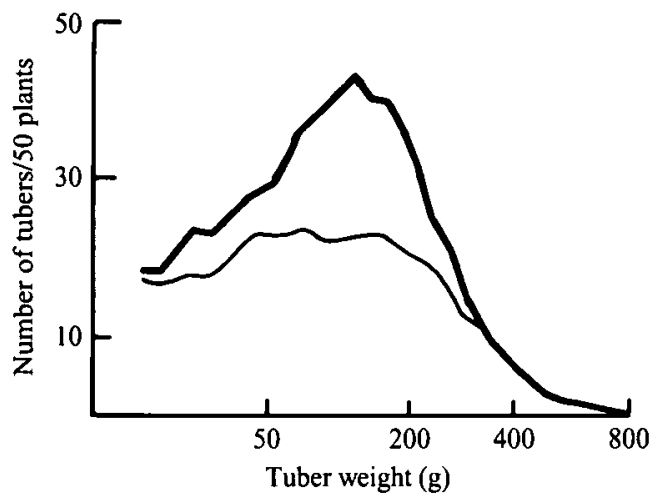

Fig. 3. Size distribution of tubers from healthy plants with healthy first neighbours $(\mathrm{HHH}, \longrightarrow$ ) and from plants with blackleg with diseased first neighbours (DDD, - ).

Ware yields also increased as competition from first neighbours decreased (Table 7), and with missing first neighbours the ware yield of healthy plants was increased by $85 \%$. The increase was proportionally less with diseased plants (47\%).
Blackleg decreased numbers of tubers $<300 \mathrm{~g}$ and especially those $50-200 \mathrm{~g}$ (Fig. 3). With healthy plants, decreasing the competition from neighbouring plants increased the numbers of tubers $>200 \mathrm{~g}$ (Fig. 4). Numbers of tubers $<100 \mathrm{~g}$ also slightly increased whereas the shape of the distribution became flatter with a decrease in tubers $100-300 \mathrm{~g}$. Diseased plants were less responsive to the effects of neighbouring plants; two healthy neighbours decreased numbers of tubers of most weights, and with decreasing competition there was a slight increase in the number of large tubers $(>300 \mathrm{~g})$. Also, when there were no first neighbours, numbers of tubers $<50 \mathrm{~g}$ were increased.

\section{Second neighbours and plants in adjacent rows}

Although the disease affected yield and tuber numbers, there were no trends with decreasing competition either from second neighbours or from plants in adjacent rows.

\section{Prediction of total and ware yield for different crop mixtures}

As second neighbours and plants in adjacent rows did not have significant effects on yield, the predicted 

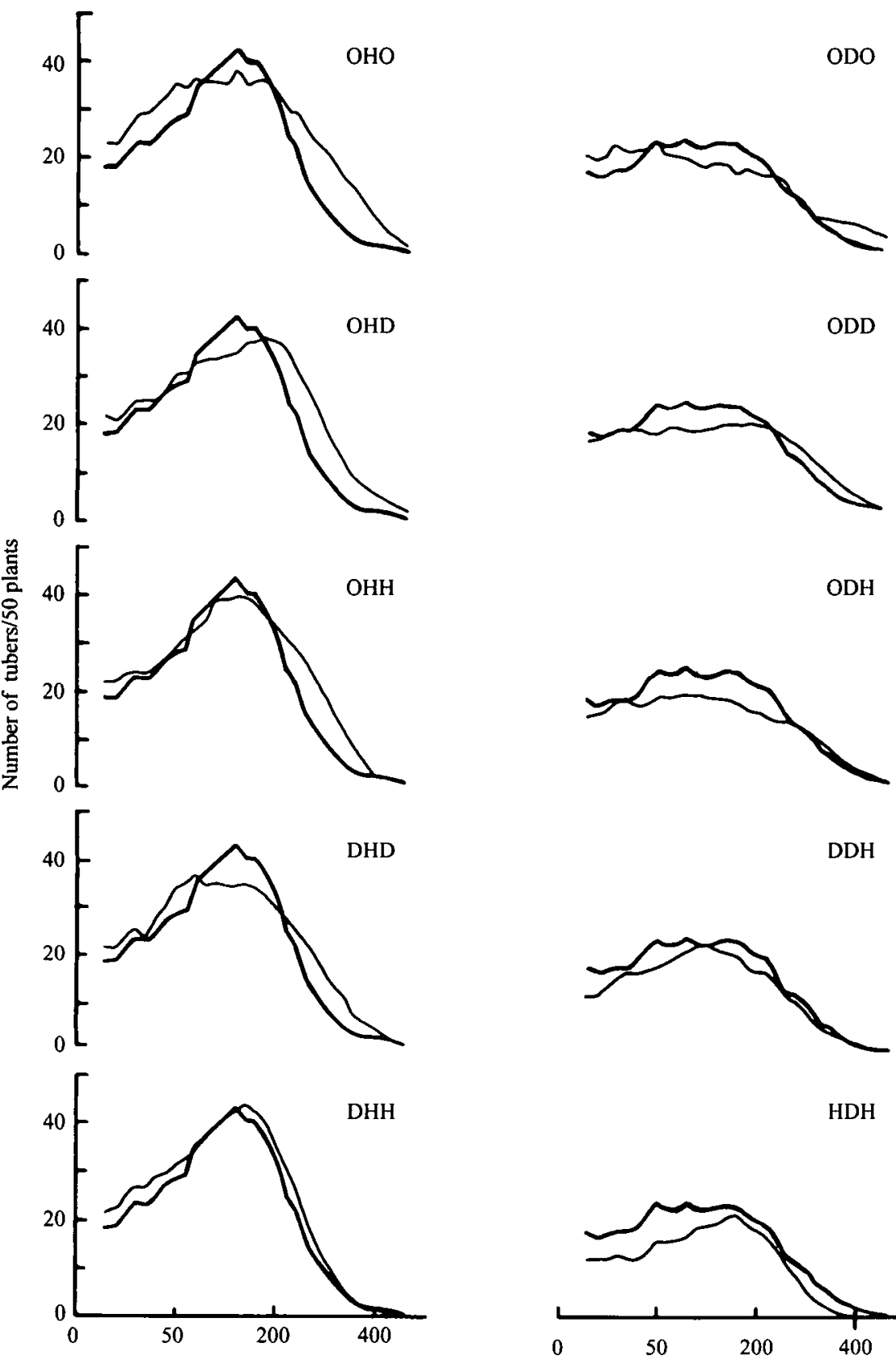

$\mathrm{DDH}$

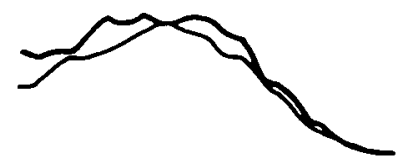

$\mathrm{HDH}$

Tuber weight (g)

Fig. 4. Size distribution of tubers from healthy plants and from plants with blackleg with different combinations of healthy $(\mathrm{H})$, diseased $(\mathrm{D})$ and missing $(\mathrm{O})$ first neighbours $(-)$. Bold lines $(-)$ show respectively distributions from healthy plants with healthy neighbours (HHH) and diseased plants with diseased neighbours (DDD) as in Fig. 3.

yield loss from crops with all plants diseased (Table 8) was similar to the difference between HHH and DDD (Table 6). In crops without missing plants, ware yield declined as the proportion of diseased plants increased, and this was in contrast to the effect found with stem canker (Table 4). Also when there were missing plants, losses were smaller with ware than total yield because with decreased competition diseased plants produced slightly more large tubers (Fig. 4). 
Table 8. Predicted yields (g/plant position) for different crop mixtures and as percentage of healthy crop yield, blackleg

\begin{tabular}{|c|c|c|c|c|c|c|c|c|c|c|c|}
\hline \multirow{2}{*}{$\begin{array}{l}\text { Missing } \\
\text { plants } \\
(\%)\end{array}$} & \multicolumn{11}{|c|}{ Diseased plants (\%) } \\
\hline & 0 & 10 & 20 & 30 & 40 & 50 & 60 & 70 & 80 & 90 & 100 \\
\hline \multicolumn{12}{|c|}{ Total yield $(\mathrm{g})$} \\
\hline 0 & 1648 & 1596 & 1543 & 1490 & 1436 & 1382 & 1327 & 1272 & 1216 & 1159 & 1102 \\
\hline 10 & 1553 & 1498 & 1442 & 1385 & 1328 & 1270 & 1212 & 1154 & 1095 & 1035 & $*$ \\
\hline 20 & 1443 & 1384 & 1324 & 1264 & 1204 & 1143 & 1081 & 1019 & 957 & $*$ & $*$ \\
\hline 50 & 1017 & 947 & 877 & 806 & 735 & 664 & $*$ & $*$ & $*$ & * & * \\
\hline 60 & 844 & 771 & 696 & 622 & 547 & $*$ & * & * & * & * & * \\
\hline
\end{tabular}

Standard errors: maximum $=56.5 ;$ minimum $=8 \cdot 2 ;$ average $=24.9$.

\begin{tabular}{|c|c|c|c|c|c|c|c|c|c|c|c|}
\hline \multicolumn{12}{|c|}{ Yield as a percentage of healthy crop } \\
\hline 0 & 100 & 97 & 94 & 90 & 87 & 84 & 80 & 77 & 74 & 70 & 67 \\
\hline 10 & 94 & 91 & 87 & 84 & 81 & 77 & 74 & 70 & 66 & 63 & * \\
\hline 20 & 87 & 84 & 80 & 77 & 73 & 69 & 66 & 62 & 58 & ${ }^{*}$ & * \\
\hline 50 & 62 & 57 & 53 & 49 & 45 & 40 & * & 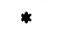 & * & $*$ & * \\
\hline 60 & 51 & 47 & 42 & 38 & 33 & $*$ & * & * & * & * & * \\
\hline \multicolumn{12}{|c|}{ Ware yield $(\mathrm{g})$} \\
\hline 0 & 1088 & 1056 & 1025 & 994 & 963 & 933 & 904 & 875 & 846 & 818 & 791 \\
\hline 10 & 1051 & 1017 & 984 & 951 & 918 & 886 & 855 & 824 & 793 & 763 & * \\
\hline 20 & 997 & 962 & 926 & 891 & 856 & 822 & 788 & 754 & 721 & * & * \\
\hline 50 & 739 & 695 & 652 & 608 & 565 & 521 & * & * & * & * & * \\
\hline 60 & 622 & 574 & 527 & 480 & 434 & $*$ & * & * & * & * & * \\
\hline
\end{tabular}

Standard errors: maximum $=55 \cdot 6 ;$ minimum $=8 \cdot 0 ;$ average $=24 \cdot 5$.

\begin{tabular}{rrllllllllll}
\multicolumn{10}{c}{ Ware yield as a percentage of healthy crop } \\
0 & 100 & 97 & 94 & 91 & 88 & 86 & 83 & 80 & 78 & 75 & 73 \\
10 & 97 & 93 & 90 & 87 & 84 & 81 & 78 & 76 & 73 & 70 & $*$ \\
20 & 92 & 88 & 85 & 82 & 79 & 76 & 72 & 69 & 66 & $*$ & $*$ \\
50 & 68 & 64 & 60 & 56 & 52 & 48 & $*$ & $*$ & $*$ & $*$ & $*$ \\
60 & 57 & 53 & 48 & 44 & 40 & $*$ & $*$ & $*$ & $*$ & $*$ & $*$ \\
\hline
\end{tabular}

\section{DISCUSSION}

Comparison of total yields from uniform populations (HHH, DDD) showed that losses from blackleg, gangrene (Hide et al. 1995) and stem canker were respectively 28,19 and $7 \%$. Similar yield decreases were found in earlier experiments when whole plots comprised healthy or diseased plants (Hide et al. 1973; Griffith et al. 1974; Adams \& Lapwood 1983) and these reflected both the extent of damage done to the seed tubers or growing plants and their ability to withstand and compensate for damage.

The diseases also altered tuber size, and losses in ware yield were respectively 26,50 and $2 \%$. Blackleg decreased total and ware yields by similar proportions because it decreased numbers of tubers over most of the size range. By contrast, gangrene decreased ware more than total yield; diseased plants had slightly more stems and produced more tubers than healthy plants and a large proportion were below ware size. Although stem canker sometimes increases the number and size of the largest tubers, for example Pentland Squire in Hide et al. (1992), it made only small differences to the tuber size distribution in this experiment. Diseased plants had slightly fewer ware and small tubers and this seemed to be compensated for by a slight increase in the mean weight of ware tubers (Table 3). However, when the effects of first and second neighbours and plants in adjacent rows were accounted for in the predicted yields, these diseases usually had smaller effects on total and ware yields.

The ability of diseased plants to compensate was demonstrated when the first neighbours were missing, and this would be equivalent to doubling the distance between plants. The total yield from blackleg plants increased by $29 \%$, compared to $56 \%$ for healthy plants, indicating that the capacity of weakened plants to compensate was impaired. By contrast, total yields from plants produced by gangrene-affected seed tubers and from plants affected with stem canker increased respectively by 59 and $63 \%$ at the wider spacing, compared to 72 and $56 \%$ for healthy plants; therefore plants from gangrene-affected tubers compensated almost as well as healthy plants and those with stem canker compensated slightly better than healthy plants. Similarly, ware yields from blackleg plants increased by $47 \%$ ( $85 \%$ for healthy plants) 
and those from plants with stem canker by $72 \%$ ( $71 \%$ in healthy plants). However, with gangrene, ware yield increased by $163 \%$ (109\% for healthy plants), indicating that many of the extra tubers produced became ware sized, and in proportionately greater numbers than for healthy plants.

In these comparisons, the effects of disease were confounded with cultivar, and differences in disease susceptibility between cultivars could influence the ability of affected plants to compensate in growth and yield. The cultivars used were among those most susceptible to the respective diseases and it might be expected that with less susceptible ones there would be less compensation. Earlier results suggested that the effects of stem canker on the growth and yield of plants will be influenced not only by the inherent susceptibility of the cultivar but also by its ability to withstand and recover from the damage (Hide et al. 1989). Furthermore, the predicted yields from different crop mixtures indicate that in the absence of diseased plants the cultivars showed different degrees of compensation for missing plants. For example, when there were $60 \%$ missing plants, we predicted that Pentland Crown would give $70 \%$ of the yield of a full plant population (Table 4 in Hide et al. 1995) whereas Pentland Squire and Désiree would yield respectively 63 and $51 \%$ (Tables 4 and 8 ). There were larger differences with ware; Pentland Crown was predicted to give $96 \%$ of the ware yield of a full population and Pentland Squire and Désirée respectively 71 and $57 \%$.

Some of the differences in compensation could have resulted from differences in growing conditions in 1987 (Pentland Crown, Pentland Squire) and 1988 (Désirée), although total amounts of rain at Rothamsted during May to August (1987, $275 \mathrm{~mm}$;
$1988,262 \mathrm{~mm}$ ) and mean soil temperature at $10 \mathrm{~cm}$ $\left(1987,14.3{ }^{\circ} \mathrm{C} ; 1988,14.7^{\circ} \mathrm{C}\right)$ were similar in the two years. Other factors that might have influenced compensation, including the vigour and physiological condition of the seed tubers at planting, were not measured.

In earlier observations over 5 years, we found from sequential sampling that tubers developed in two populations and that often the ware fraction comprised only a small proportion of the tubers initiated (Hide \& Welham 1992). Size distributions of cv. Pentland Squire at harvest in 1987 also showed two populations and there was an indication of two populations from healthy Pentland Crown plants in the experiment with gangrene (Hide et al. 1995). However, in both experiments the first population of small tubers declined as the competition from neighbouring plants decreased and was not evident when plants were spaced wide apart. As total tuber numbers similarly increased, the results indicate that competition from neighbouring plants restricted the number of tubers that moved into the second population and also that a proportion of the small tubers were resorbed. The size distributions of $\mathrm{cv}$. Désirée at harvest in 1988 did not show a distinct population of small tubers, but in the earlier observations, distributions at harvest sometimes showed as a symmetrical pattern although results from earlier sampling had confirmed that crops did develop as two populations. This suggests that growing conditions or disease had encouraged resorption of many small tubers.

We thank R. A. Bailey for advice on experimental design. The work was supported by the Ministry of Agriculture, Fisheries and Food.

\section{REFERENCES}

ADAMS, M. J. \& LAPWOOD, D. H. (1983). The effect of Erwinia carotovora subsp. atroseptica (blackleg) on potato plants. II. Compensatory growth. Annals of Applied Biology 103, 79-85.

Griffith, R. L., Hide, G. A., Hirst, J. M. \& Stedman, O. J. (1974). Effects of gangrene (Phoma exigua) on potatoes. Annals of Applied Biology 77, 237-250.

Hall, M. (1986). Combinatorial Theory. New York: Wiley.

Hide, G. A. (1981). Fungus diseases on potato seed tubers planted in England and Wales, 1963-76. Annals of Applied Biology 98, 377-393.

Hide, G. A. \& Welham, S. J. (1992). Observations on the bulking and development of tuber size distribution in maincrop potatoes at Rothamsted in 1964-75. Potato Research 35, 235-247.

Hide, G. A., Hirst, J. M. \& Stedman, O. J. (1973). Effects of black scurf (Rhizoctonia solani) on potatoes. Annals of Applied Biology 74, 139-148.
Hide, G. A., Read, P. J. \& Sandison, J. P. (1985a). Stem canker (Rhizoctonia solani) of maincrop potatoes. 1 . Development of the disease. Annals of Applied Biology 106, 413-422.

Hide, G. A., Read, P. J. \& Sandison, J. P. (1985b). Stem canker (Rhizoctonia solani) of maincrop potatoes. II. Effects on growth and yield. Annals of Applied Biology 106, 423-437.

Hide, G. A., Read, P. J., Firmager, J. P. \& Hall, S. M. (1989). Stem canker (Rhizoctonia solani) on five early and seven maincrop potato cultivars. II. Effects on growth and yield. Annals of Applied Biology 114, 267-277.

Hide, G. A., ReAD, P. J. \& Hall, S. M. (1992). Stem canker (Rhizoctonia solani) on three early and three maincrop potato cultivars: effects of seed tuber size on growth and yield. Annals of Applied Biology 120, 391-403.

Hide, G. A., Welham, S. J., Read, P. J. \& Ainsley, A. E. (1995). Influence of planting seed tubers with gangrene 
(Phoma foveata) and of neighbouring healthy, diseased and missing plants on the yield and size of potatoes. Journal of Agricultural Science, Cambridge 125, 51-60.

LapwoOd, D. H., Read, P. J. \& GaNs, P. T. (1985). The field susceptibility of potato varieties to blackleg caused by Erwinia carotovora subsp. atroseptica. Journal of the National Institute of Agricultural Botany 17, 107-116.

Pérombelon, M. C. M. (1972). The extent and survival of contamination of potato stocks in Scotland by Erwinia carotovora var. carotovora and $E$. carotovora var. atroseptica. Annals of Applied Biology 71, 111-117. 